\title{
Two conceptions of fraction equivalence
}

\author{
Pernille Ladegaard Pedersen ${ }^{1}$ (D) $\cdot$ Mette Bjerre $^{2}$ (i)
}

Accepted: 17 January 2021 / Published online: 9 March 2021

(C) The Author(s) 2021

\begin{abstract}
In this study, we present a mathematical analysis distinguishing two conceptions of equivalence: proportional equivalence and unit equivalence. These two conceptions have distinct meanings in relation to equivalent fractions: one is grounded in proportionality, while the other is grounded in equal wholes. We argue that (a) the distinction of equivalence gives a unified framework of equal fractions that has not previously been described in the literature; (b) a conceptual understanding of both fraction equivalences is integral to understanding rational numbers; and (c) knowledge of both conceptions of equivalence is important for developing a conceptual understanding of fraction arithmetic. Past research has largely overlooked the distinction between the two types of equivalence. However, this may provide an important foundation for central topics that build on equivalence, and a better understanding of these two types of equivalence may support a more flexible understanding of fractions. Last, we propose future directions for teaching equivalence in mathematics.
\end{abstract}

Keywords Fractions $\cdot$ Equivalence $\cdot$ Arithmetic $\cdot$ Addition $\cdot$ Subtraction

\section{Introduction}

Fractions is one of the most important mathematical topics that students learn at the primary and secondary school levels; it is also one of the most multifaceted. An important part of this topic is understanding equivalence. Research has continually shown that students' conceptual understanding of fractions is central to their mathematical development. This understanding is the foundation for learning more advanced mathematics, such as algebra and statistics (Bailey,

Pernille Ladegaard Pedersen

plap@learning.aau.dk

Mette Bjerre

mebj@via.dk

1 Department of Culture and Learning, Aalborg University, 8900 Aalborg, Denmark

2 Forskningscenter for Pædagogik og Dannelse, Via University College, Aarhus, Denmark 
Hoard, Nugent, \& Geary, 2012; Booth \& Newton, 2012; Siegler et al., 2012; Siegler, Fazio, Bailey, \& Zhou, 2013). Unfortunately, many students struggle to develop an understanding of fractions (Torbeyns, Schneider, Xin, \& Siegler, 2015), and this difficulty persists as they advance through the school system (Fazio, DeWolf, \& Siegler, 2016; Schneider \& Siegler, 2010). In particular, previous research has found that many students have trouble constructing or identifying equivalent fractions, and it is a difficult concept for students to grasp (Behr, Wachsmuth, Post, \& Lesh, 1984; Kamii \& Clark, 1995; Wong, 2010). Many of the difficulties related to fraction equivalence have often been connected with whole number bias (e.g., Ni \& Zhou, 2005; Van Hoof, Lijnen, Verschaffel, \& Van Dooren, 2013), where students have a tendency to let whole number knowledge interfere with their concept of rational numbers, including fractions.

Students' first experiences with quantities involve natural numbers, where every number represents a unique quantity. When students subsequently encounter rational numbers, seemingly different numbers describe the same quantity in the fraction notation, for example $\frac{1}{4}$ and $\frac{2}{8}$ (Ni \& Zhou, 2005). This can be a stumbling block for many students and may be the cause of students' tendency to use an algorithm for equivalent fraction tasks without understanding how or why it works (Ni, 2001; Stafylidou \& Vosniadou, 2004; Wong \& Evans, 2007).

A key issue in understanding the concept of fractions is that different understandings and uses of fractions are connected to different representations of fractions. Each of these representations offers unique advantages or challenges for students' conceptual development and thus their understanding of fraction equivalence (Behr, Harel, Post, \& Lesh, 1993; Behr, Lesh, Post, \& Silver, 1983; English \& Halford, 1995; Kamii \& Clark, 1995; Kieren, 1976). For example, it is easier for students to understand equivalence when doing splitting activities, as these activities are founded in the ability to divide wholes into equal parts (Kamii \& Clark, 1995). English and Halford (1995) argue that the determination of whether fractions are equivalent entails an understanding of the equivalence in the proportional relation between the numerator and the denominator within two sets of fractions. This is because students have to identify the equivalence regardless of a noticeable increase or decrease in the numerator or denominator. In other words, fraction equivalence can be seen as the invariance of the quotient or the multiplicative relation between the numerator and denominator (Behr, Harel, Post, \& Lesh, 1992; Ni, 2001). When considering equivalence in a broader context, and not inclusively connected to fractions, Kaput and West (1994) introduce three features of understanding equivalence:

- Numeral equivalence is strictly connected to numbers.

- Semantic equivalence is connected to a broader interpretation, for example, the understanding of which context the equivalence is relevant to and how. For example, is it better to say two blue shirts for every green shirt in the store, or seven green shirts and 14 blue shirts in the store?

- Homogeneity is related to the genuine concept of uniformity in the underlying concept of the situation. For example, do we have the same interpretation of colour? When can we determine a colour as green? And when is a green colour turning into a blue interpretation?

However, Kaput and West do not examine whether numeral equivalence can differ in its interpretation. Further, it is worth mentioning that previous studies argue that the ability to select or make suitable units plays an important role in the development process of both 
rational and natural numbers concepts (e.g., Vamvakoussi, 2015). However, no attempt has been made to explore the different understandings of equivalence connected to the different constructs of fractions.

Researchers agree that it takes time for students to develop their conceptual understanding of fractions, and that the complexity of learning fractions lies in their multifaceted nature (Charalambous \& Pitta-Pantazi, 2007; Lamon, 2012; Streetland, 1991). Hence, students need experience with different representations of fractions, and such exposure is central to the learning of equivalence.

\section{Purpose of the present study}

Previous research suggests the need for a discussion of how students understand equivalence, and how their understanding of equivalence can be developed earlier. We introduce two conceptions of fraction equivalence: unit equivalence and proportional equivalence. Our analysis is structured around Kieren's $(1976,1980)$ semantic framework, which captures the complex and multifaceted nature of fractions. We are aware of the limitations and acknowledge that understanding fractions involves a multidisciplinary approach, incorporating, for example, cognitive psychology (e.g., Siegler et al., 2012), neuroscience (e.g., DeWolf, Chiang, Bassok, Holyoak, \& Monti, 2016) and didactics (e.g., Tzur, 1999). Nevertheless, in our contribution to this multidisciplinary research field, we investigate the abovementioned conceptions of fraction equivalence from a mathematical perspective, using Kieren's (1976, 1980) semantic framework because it contributes to teachers' content knowledge of fractions. Our analysis differs from previous analyses by including two conceptions of equivalence: one based on an internal numerical unit approach and one based on an external proportional approach. The two conceptions of equivalence lead to different understandings of fraction equivalence, which has been overlooked in previous studies. We use these two conceptions of equivalence as the basis for the mathematical analysis of different fraction equivalence conceptions.

In our analysis, we first present the mathematical definition of equivalence and the distinction between unit equivalence and proportional equivalence. This is followed by a presentation of the different fraction subconstructs, based on Kieren's (1976) framework, as well as an analysis of which conception of equivalence is present in each subconstruct. We then connect equivalence and its associated forms of reasoning to how fraction arithmetic is taught. We have chosen to focus on different examples of addition and subtraction tasks as these are often the first fraction problems students meet, and they correspond to children's development of either conceptual understanding or mere procedural knowledge. We expect that our analysis will create new ways of understanding mathematical topics and lead to new insights for teaching fraction equivalence. These insights could then be used in future empirical research focused on developing and supporting students' learning of fractions.

\section{Mathematical analysis}

The notation of a fraction is defined as $\frac{a}{b}$. For the purpose of this analysis, the term 'fraction' refers to a rational number such that in $\frac{a}{b}$ both $a$ and $b$ are integers and $b \neq 0$. Our mathematical analysis starts with the understanding of fraction equivalence. 


\subsection{Definitions and distinction between unit and proportional equivalence}

The equal sign is the canonical example of an equivalence relation. If ' $=$ ' is an equivalence relation, then for any $a, b$ and $c$ we have the following: the reflexive property $(a=a)$, the symmetric property (if $a=b$, then $b=a$ ) and the transitive property (if $a=b$ and $b=c$, then $a=$ $c$ ). A set $S$ with an equivalence relation ' $=$ ' can be divided into equivalence classes, where the two elements $s$ and $t$ in $S$ are in the same equivalence class if, and only if, they are equivalent $(s=t)$. Hence, we can define the set $S=\left\{\frac{a}{b}\right.$, for $\left.b \neq 0\right\}$. For the two elements $s$ and $t$ of $S, s$ and $t$ will have the forms $s=\frac{a}{b}$ and $t=\frac{c}{d}$, respectively. We can define the equivalence relation $\frac{a}{b}=\frac{c}{d}$ if and only if $a \cdot d=c \cdot b$.

Obviously, the numbers $\frac{2}{3}$ and $\frac{4}{6}$ have the same magnitude. To understand why these two fractions are the same, one could draw two circles of equal area, divide one circle into three equal parts and colour two parts, and divide the other circle into six equal parts and colour four parts. This way, it is possible to see that the numbers are in fact equal since an equal area of the two circles is coloured. This is only true when the two circles have the same area; that is, if the unit is the same (Fig. 1). If we talk about the unit as defining what the 'whole' is, we can talk about fractions as equal when they are the same part of equal wholes (Yoshida \& Sawano, 2002). We call this equivalence unit equivalence.

Fractions can also be interpreted as the ratio between the numerator and denominator, in which case the result is sometimes unitless. Hence, we can also talk about the equivalence of fractions when they define the same proportionality. We call this equivalence proportional equivalence. Take the following example: 'I have eaten two pieces of my pizza, which was in six pieces. You have eaten one of your three bananas. We have eaten the same fraction of our food'. Two pieces of pizza are of course not the same as one banana, but the proportionality is

\begin{tabular}{l|l|l}
\hline Representation & Unit equivalence \\
\hline Example & $\begin{array}{l}\text { Bill eats } \frac{1}{4} \text { of the cake and } \\
\text { Sara eats } \frac{2}{8} \text { of the cake. } \\
\text { Each of the numbers has } \\
\text { the unit "cake", and it is the } \\
\text { same size. }\end{array}$ & $\begin{array}{l}\text { Bill eats one out of three } \\
\text { bananas. Sara eats two out of } \\
\text { six pieces of pizza. They have } \\
\text { eaten the same fraction of their } \\
\text { food. }\end{array}$ \\
$\begin{array}{l}\frac{1}{4} \text { cake }=\frac{2}{8} \text { cake } \\
\text { Equal units }\end{array}$ & $\begin{array}{l}\frac{1 \text { (banana) }}{3 \text { (bananas) }} \\
\text { No unit }\end{array}$ \\
\hline
\end{tabular}

Fig. 1 Two conceptions of equivalence 
the same. It is important to emphasise that unit equivalence automatically includes proportional equivalence, but proportional equivalence does not include unit equivalence.

\subsection{Analysis of equivalence within the subconstructs of fractions}

In the mid-1970s and early 1980s, Kieren (1976), Vergnaud (1983) and Freudenthal (1983) independently identified the various subconstructs, aspects or objects of fractions. Each of these authors developed a framework aimed at capturing the multifaceted nature of fractions. Vergnaud (1983) placed the concept of fractions within the broader multiplicative conceptual field, while Freudenthal (1983) focused on the development of different aspects of partitioning. For his part, Kieren $(1976,1980)$ focused on rational numbers as a set of five interrelated but distinct subconstructs: part-whole, measure, operator, quotient and ratio. It is these subconstructs that we use as our starting point in this article.

Before doing so, however, it is worth noting that over the past decades, Kieren's framework has gone through multiple iterations: sometimes expanding to include additional subconstructs, sometimes contracting as subconstructs are combined. Kieren's original 1976 framework did not perceive part-whole as a unique subconstruct but rather as an integrated part of the other subconstructs. This version also included two additional subconstructs: ordered pairs and decimals. Later, Kieren separated part-whole as its own subconstruct (Kieren, 1980). In 1983, the Rational Number Project by Behr et al. restated Kieren's framework, using slightly different terms and established part-whole as a subconstruct underlying all the others as shown in Fig. 2. In his later work, Kieren expanded the model to include several additional levels (Kieren, 1988, 1993).

These five subconstructs, part-whole, measure, operator, quotient and ratio, are not universal, and other semantic frameworks exist for analysing fractions, such as Ohlsson's (1987) comparison between quantities, division of quantities and counteracting changes and Hecht, Close, and Santisi's (2003) definition of fractions as how much is present in a rational quantity (part-whole and measurement). Further, Kieren's framework has been criticised for being an adult view of fractions and therefore insufficient for investigating students' construction of fractional knowledge (Charalambous \& Pitta-Pantazi, 2007; Olive \& Lobato, 2008). Nevertheless, for our purposes, Kieren's (1976) framework captures the multifaceted nature of the concept, and we find that it includes or overlaps with other suggested frameworks. Thus,

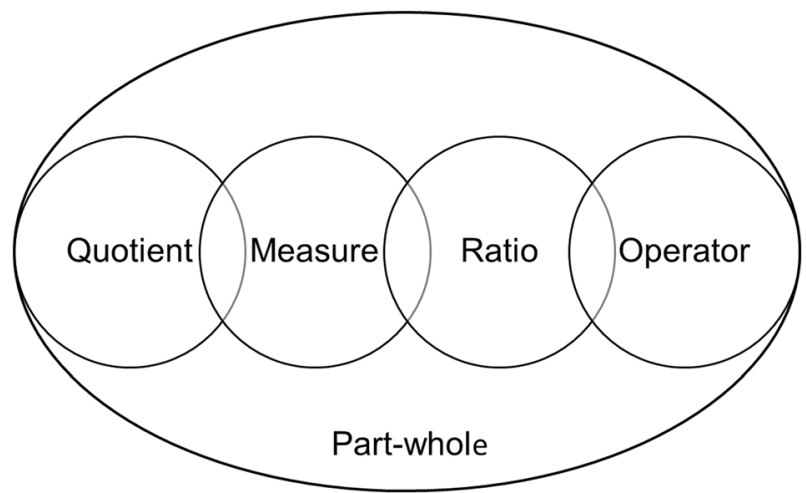

Fig. 2 The theoretical model linking the five subconstructs of fractions, developed from Behr et al.'s model (1983) 
we now turn to the presentation of Kieren's five subconstructs to analyse them in terms of which conceptions of equivalence they contain.

\subsection{The part-whole subsconstruct}

The part-whole subconstruct is based on the student's ability to partition either a continuous quantity or several discrete objects into equal-sized parts or sets (Behr et al., 1983; Charalambous \& Pitta-Pantazi, 2007; Marshall, 1993). This is often how the concept of fractions is introduced in school (Lamon, 2012; Vasconcelos, da Mamede, \& Dorneles, 2017). This subconstruct describes the number of equal-sized partitioned parts denoted by denominator $b$, while numerator $a$ defines the number of parts (Behr et al., 1983; Marshall, 1993).

When the fraction refers to the same relative amount-for example, when $\frac{1}{4}$ refers to one pizza slice out of four and one blue t-shirt out of four t-shirts - this is proportional equivalence. We define proportional equivalence as when the proportional relation between partwholes is the same across different representations. Conversely, in unit equivalence, the relative amount or magnitude of fractions is the same. For example, $\frac{1}{4}$ of a pie is the same as $\frac{2}{8}$ of the pie or $\frac{3}{12}$ of the pie because they describe the equivalent parts of the same-sized whole-the pie (Fig. 3).

When the whole varies between the different representations, the student must understand that proportionality is the central point. Thus, the relation between the part and the whole that does not differ is fundamental for proportional equivalence. However, the whole must be the same before we can define the equivalence as unit equivalence. When comparing $\frac{1}{4}$ and $\frac{2}{8}$, for example, we might assume the sizes of the wholes are the same, such that taking $\frac{2}{8}$ and $\frac{1}{4}$ of the same-sized pizza gives the same amount of pizza. However, if we were to take $\frac{1}{4}$ of a familysized pizza and $\frac{2}{8}$ of a smaller pizza, this would give different amounts of pizza, meaning that $\frac{1}{4}$ and $\frac{2}{8}$ in this case are not of equal size. This is the concept of the equal whole (Behr et al.,

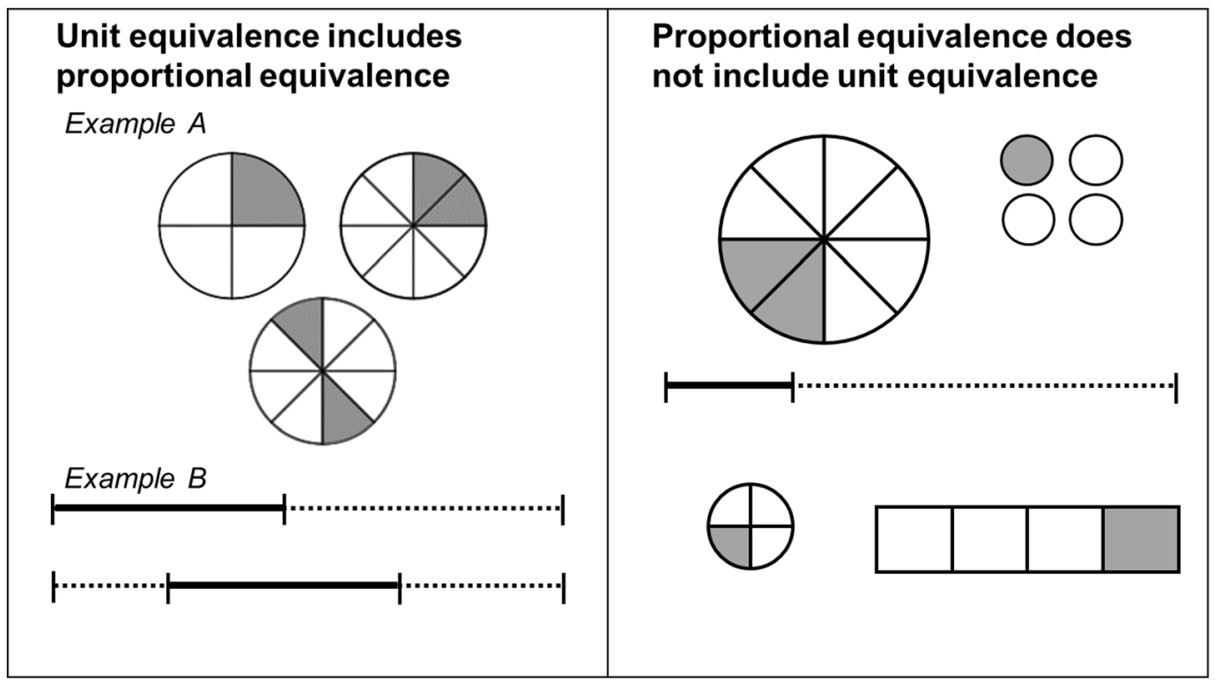

Fig. 3 Examples of proportional and unit equivalence. Unit equivalence always includes proportional equivalence, whereas proportional equivalence recognises that all representations are $\frac{1}{4}$ 

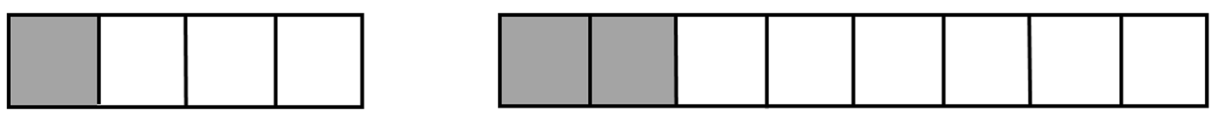

Fig. 4 Example of no equal-wholes when comparing $\frac{1}{4}$ and $\frac{2}{8}$. This is proportional equivalence and not unit equivalence

1984; Hart, 1988; Smith, 1995; Yoshida \& Kuriyama, 1995; Yoshida \& Sawano, 2002), and research has shown that is very difficult for students to grasp (Hart, 1988; Peck \& Jencks, 1981; Yoshida \& Sawano, 2002). Without this understanding of the equal whole, when students are asked to compare the size of the fractions $\frac{2}{8}$ and $\frac{1}{4}$ (as in Fig. 4), they would have to compare the proportional relation between the colored part and the noncolored part to determine the equivalence.

Based on the above discussion, it is apparent that the part-whole subconstruct involves understanding the concepts of both equal part and equal wholes. Further, both proportional and unit equivalence are connected to whether an equal whole is present.

\subsection{The quotient subconstruct}

The fractional notation $\frac{a}{b}$ can also refer to the division operation; hence, $\frac{a}{b}$ can be presented as $a \div b$, indicating a quotient. The fraction $\frac{a}{b}$ then indicates the numerical value obtained from the division (Charalambous \& Pitta-Pantazi, 2007; Kieren, 1980; Marshall, 1993). The quotient subconstruct involves a process where a two-entity versus a one-entity phenomenon is present. The first step in this process is looking at the fractions as two quantities (the numerator and the denominator), with the numerator seen as a dividend and the denominator as the divisor. The result is the process of partitive or measurement division of a single quantity (Behr et al., 1993).

In the quotient subconstruct, partitive and measurement division lead into proportional and unit equivalence. In partitive division in the context of the quotient subconstruct, the denominator stands for the number of recipients, and the numerator is the quantity that has to be shared. The equivalence in this context is apparent in the following example: when two children share one pizza, they get the same amount of pizza as when six children share three pizzas, if the pizzas are the same size. When divided, the amount of pizza received by each child is equal, and there is an equal unit present - in other words, unit equivalence (Fig. 5).

By contrast, in measurement division, the quotient is the result of the number of groups when dividing an amount into groups of a given size. Consider the expression $8 \div 3$. Imagine we have eight buns, and we have to make bags with 3 buns in each. We have enough buns to fill two bags and $\frac{2}{3}$ of a bag. This is equivalent to $16 \div 6$ where we have 16 buns, and we have to make bags with six buns in each. Again, we can fill two bags and $\frac{2}{3}$ of a bag. Whether this is unit equivalence or proportional equivalence depends on the size of the buns in the two scenarios. If each of the eight buns is parted into two, making 16 buns, then each bag will contain the same volume of buns; either three large buns or six buns of half the size. In this case, the equivalence will be unit equivalence. Conversely, if the size of the buns remains the same (i.e., the amount of dough used for the total buns in the second scenario is twice that in the first), then the bags will not have the same volume of buns. However, as the scenarios result in the same proportion of bags, there is proportional equivalence (Fig. 6). The importance of quotient has been emphasised by research (e.g., Vasconcelos et al., 2017) where the quotient seems to lead students to grasp the inverse relationship between the quantities in the quotient situation compared to the part-whole situation. 

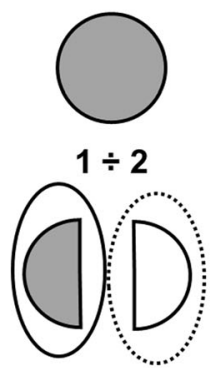

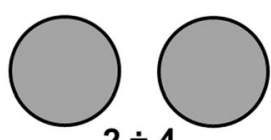

$2 \div 4$

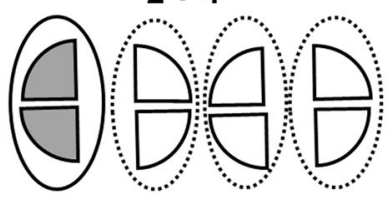

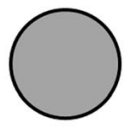

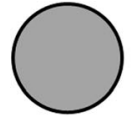

$3 \div 6$

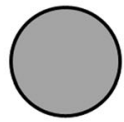

8
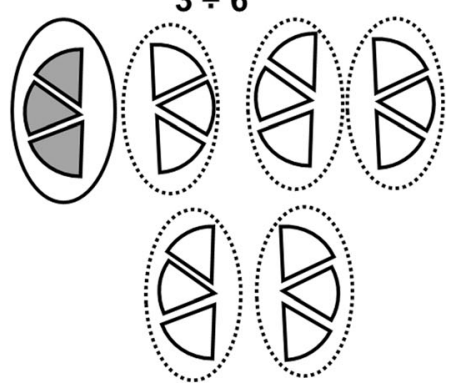

Fig. 5 Example of partitive division-unit equivalence 
We argue that in the quotient subconstruct, both unit and proportional equivalence appear. When the division is partitive, there will always be a unit equivalence. However, when measurement division is applied, both kinds of equivalence can be present, depending on whether you look at the original amount as being constant or not.

\subsection{The measure subconstruct}

The measure subconstruct is connected to two interpretations: that the fraction is a number, and that the fraction is a measure, distance or size (Charalambous \& Pitta-Pantazi, 2007). Therefore, this subconstruct includes an understanding of unit fractions as a unit of measurement (Behr et al., 1983; Behr et al., 1993; Kieren, 1980; Marshall, 1993). This subconstruct has been defined as the unit distance to a certain point from a starting point and has therefore often been connected to the number line representation (Charalambous \& Pitta-Pantazi, 2007; Marshall, 1993). However, a broader approach has also been suggested to include other representations within it, such as paper strips, chips and areas (Kieren, 1976; Lamon, 2012).

The equivalence in this subconstruct is mostly unit equivalence, as the measurement of a distance must involve a defined unit (Marshall, 1993). Unit equivalence can be seen as the same stopping-off point. For example, when starting at zero, we stop at the same place when we go the distances described as $\frac{1}{4}$ and $\frac{2}{8}$. There are two different interpretations connected to the understanding of equivalence on the number line, depending on how the whole is defined. In the first interpretation, the unit of measurement can be divided into ever smaller subunits, resulting in different fraction names, each of which is connected to a unique rational number (Ni, 2001). Consider $\frac{1}{2}=\frac{2}{4}$ (Fig. 7). Here, the distance of 1 can be divided into two equal parts and $\frac{1}{2}$ refers to one of those parts. The same distance of 1 can also be divided into four parts, $\frac{1}{4}$, and two of these parts are equal to the distance $\frac{1}{2}$. This is a unit equivalence connected to the number line.

The second interpretation recognises that equivalent fractions are represented on a number line which is connected to the equivalence of a quotient as partitive division. As shown by the second set of number lines in Fig. 7, the numerators of $\frac{1}{4}$ and $\frac{2}{8}$ refer to different wholes (1 and 2 , respectively) on the number line. As shown, 1 divided into four equal parts gives the same

a
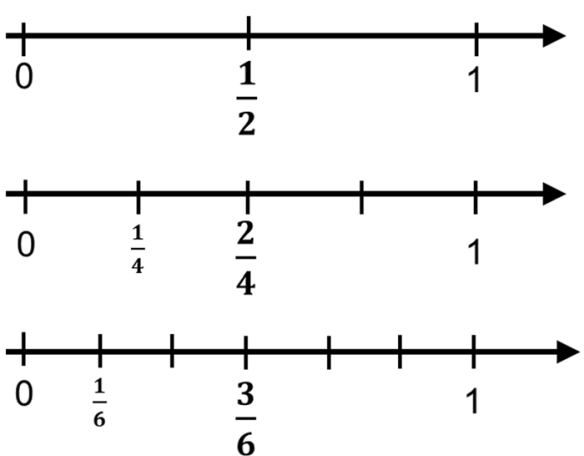

The whole is constant, and the unit-fractions differ (connected to part-whole). b

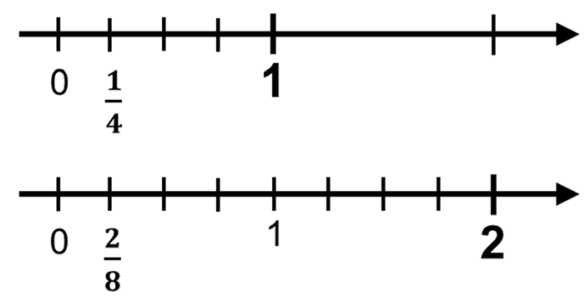

Fig. 7 Two different interpretations of unit equivalence in the measure subconstruct 


\section{The whole}
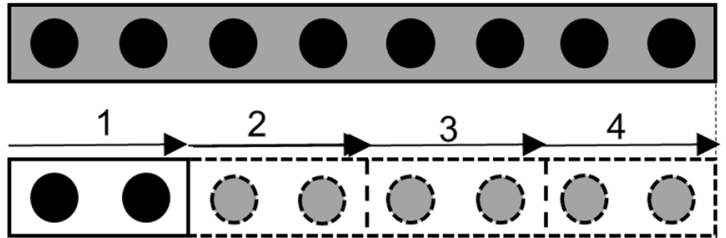

4 times

Unit of 2

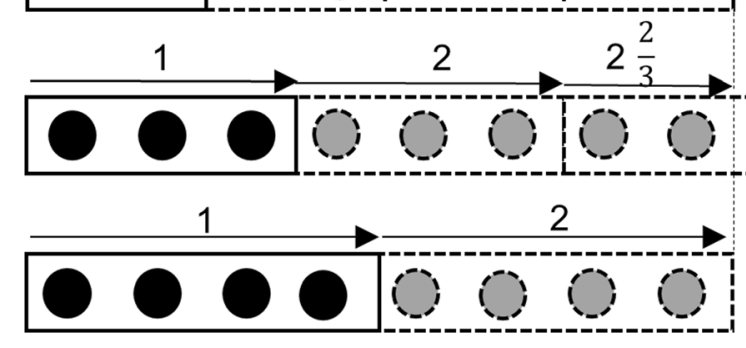

Unit of 3

Unit of 4

$2 \frac{2}{3}$ times

\section{Proportional equivalence}
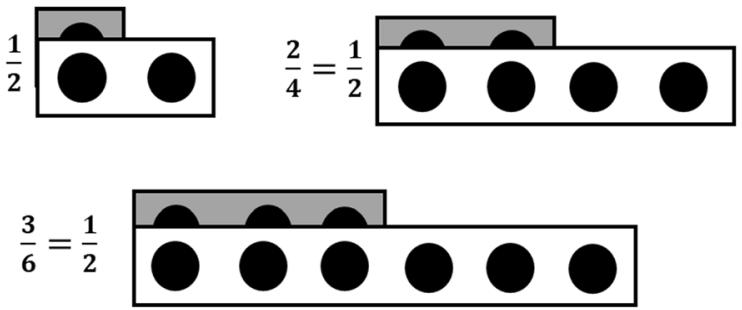

Fig. 8 Measurement division in the subconstruct measure - proportional equivalence

distance as 2 divided into eight equal parts. The wholes differ, but the parts stay the same. The distinction between the two interpretations is whether the starting point is to find the unit fraction $\left(\frac{1}{a} \cdot b\right)$ or the whole and then the unit $\left(b \cdot \frac{1}{a}\right)$.

Kieren (1976) originally proposed that both partitive and measurement division could be used in the measure subconstruct, and Lamon (2012) later followed by arguing in favour of the different defined measuring units. Measurement division involves proportional equivalence. As shown in Fig. 8, a unit defined as having a length of 2 can only go into a length of 1 half a time. Likewise, a unit defined as having a length of 4 can only go into a length of 2 half a time (Lamon, 2007, 2012).

To sum up, as in the quotient subconstruct, in the measure subconstruct unit equivalence appears when the understanding is based on partitive division. Conversely, when the understanding is based on measurement division, only proportional equivalence is present. Therefore, in the measure subconstruct, the wholes remain the same size. Thus, measuring must involve a defined unchangeable whole that we want to know the size of. For unit equivalence, there are two interpretations based on how the whole is defined. In the first interpretation, the whole is the same, and you begin by finding the unit fraction. In the second interpretation, the whole differs, and you begin by finding the different parts; that is, the unit.

\subsection{The ratio subconstruct}

The ratio subconstruct is defined as a relation that covers the notion of the two relative magnitudes: the relation between the numerator and denominator. Therefore, it can be 


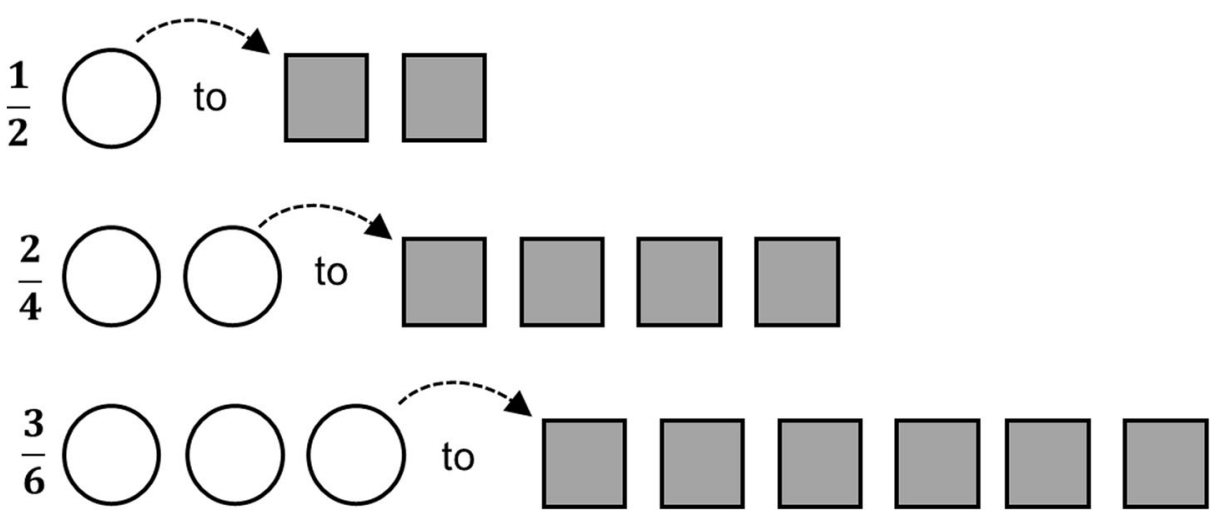

Fig. 9 Example of equivalence in the ratio construction

considered a comparative index (i.e., the numbers' proportional relation) rather than a number (Behr et al., 1983; Charalambous \& Pitta-Pantazi, 2007; Lamon, 2007, 2012). Unlike the previously described subconstructs, the ratio subconstruct does not require partitioning of the object. To illustrate the difference between the quotient and ratio, a ratio of $\frac{4}{5}$ can be explained as four apples for every five students, while the quotient would be five students sharing four apples, meaning that every student has $\frac{4}{5}$ of an apple (Marshall, 1993).

Behr et al. (1983) considered the ratio subconstruct to be the natural way to assist students in developing the concept of fraction equivalence. When looking at fraction notation, students are looking at the relation between the two integers of the numerator and denominator. For example, when the denominator is twice as large as the numerator, the fraction is equal to $\frac{1}{2}$. This means that the notation is interpreted as the relation between two separate quantities (Fig. 9). Therefore, the ratio subconstruct is connected to understanding fractions as equivalence classes $\left[\frac{1}{4}\right]=\left\{\frac{1}{4}, \frac{2}{8}, \frac{3}{12}, \ldots\right\}$ (Behr et al., 1983; Kieren, 1976, 1980). A fraction can thus be seen as an ordered pair of numbers in the form $\frac{a}{b}$ and described as a proportion in which there is a proportional relation between $a$ and $b$. The ratio remains constant. This helps to explain the equivalence between fractions such that $\frac{1}{4}=\frac{2}{8}$ as the ratio is constant from 1 to 4 and 2 to 8. Proportional equivalence is the only concept of equivalence present in the ratio subconstruct.

\subsection{The operator subconstruct}

The operator subconstruct is a given value or region that needs to be operated on to find a second value or region. It is often described as a function. The operator can be regarded as a function applied to some object (e.g., a number or set; Behr et al., 1993; Charalambous \& PittaPantazi, 2007; Marshall, 1993). This subconstruct, which has developed over time (Behr et al., 1983; Behr et al., 1993; Kieren, 1976), is complex and requires an understanding of composition, reversibility and proportionality (Kieren, 1976). An operator is used when, for example, a student wants to transform a drawn figure into a new figure that is $\frac{1}{3}$ of the original size or wants to transform a recipe so that a cake is $\frac{5}{2}$ times bigger. Unlike the other subconstructs, the operator subconstruct is considered an entity rather than an ordered pair of numbers. 
Originally, Behr et al. (1983) separated the operator subconstruct into two concepts: a stretcher/shrinker and a duplicator/partition-reducer. The choice of conception depended on whether the operation was being performed on a continuous object (length) or a discrete set. Later, Behr et al. (1993) added further conceptions. As shown in Fig. 10, the difference between the two interpretations is that the stretcher/shrinker operates on each unit such that $\frac{1}{4}$ of four apples is four quarter apples. In this case, the operation yields the same number of units, but they are now of a different size. By contrast, the duplicator/partition-reducer operates on the whole amount such that $\frac{1}{4}$ of four apples is one apple. In this case, the result of the duplicator/partition-reducer operation is a different number of units of the same size as the original unit.

According to Behr et al. (1983), the operator subconstruct of a rational number is valuable in developing an understanding of fraction equivalence. One way to understand equivalence in the operator subconstruct is to comprehend that there exists an infinite number of equivalent operators; for example, taking $\frac{3}{4}$ of 16 is equal to taking $\frac{6}{8}$ of 16 (Kieren, 1976; Marshall, 1993). Here, we find both unit equivalence and proportional equivalence. As an example of unit equivalence, $\frac{3}{4}$ of 16 pizzas is equal to $\frac{6}{8}$ of the same 16 pizzas. For proportional equivalence, consider a situation in which every ingredient in a recipe is reduced by $\frac{3}{4}$. Reducing $500 \mathrm{~g}$ of flour by $\frac{3}{4}$ is not the same as reducing a litre of milk by $\frac{3}{4}$, as flour and milk are not the same; however, we do end up with the same proportion of each ingredient.

Behr et al. $(1983,1993)$ argue that the operator subconstruct can support the understanding of the equivalence of fractions, and that the function machine (Fig. 11) can help develop this

a
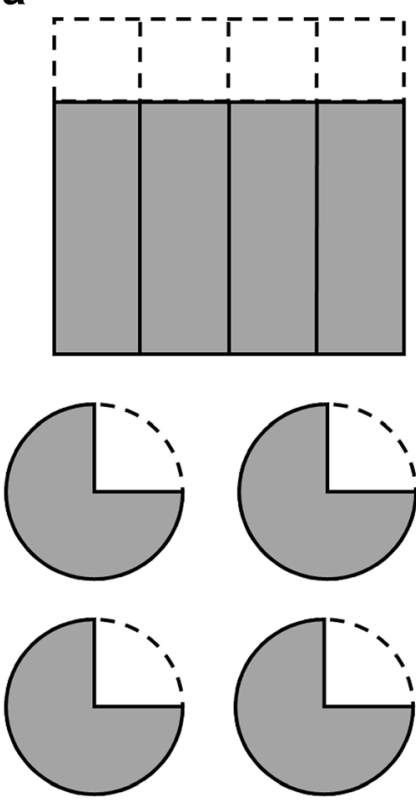

$4 \cdot\left[\frac{3}{4}\right.$ of a unit $]$ b
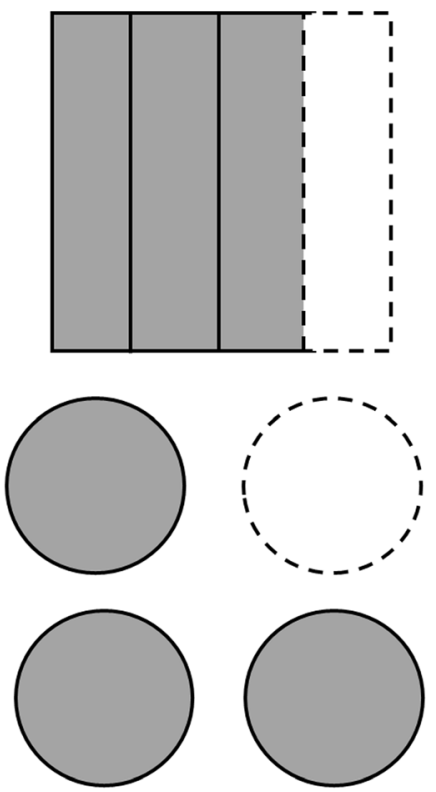

$\frac{3}{4} \cdot[4$ units $]$

Fig. 10 Different concepts of $\frac{3}{4}$ of 4 . a The same number of unit of different size. b Different number of units of the same size 


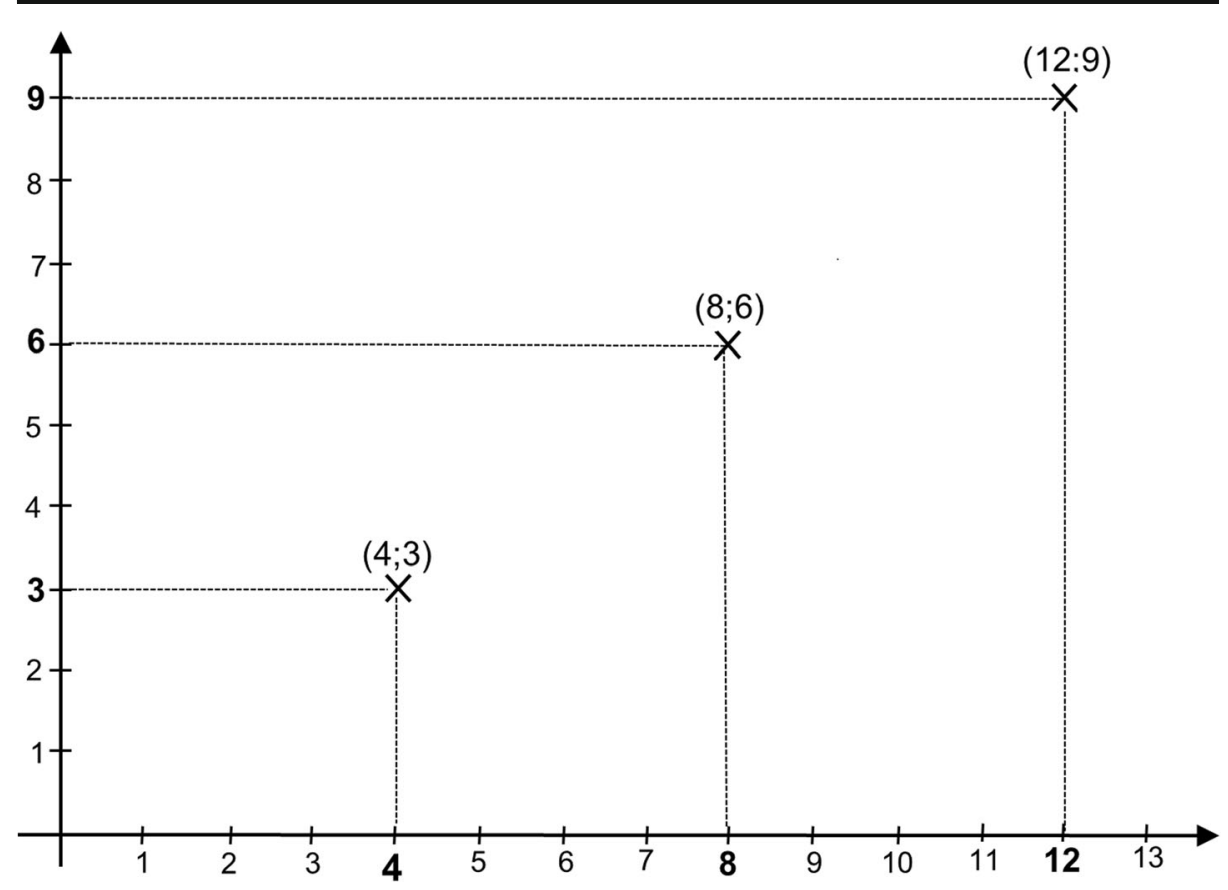

Fig. 11 Example of a $\frac{3}{4}$ function machine

understanding. In a function machine, the quantity upon which the operator works is transformed into a new quantity with a ratio of input to output equal to the ratio of the operator's numerator and denominator (Behr et al., 1983, 1993; Charalambous \& Pitta-Pantazi, 2007). In Fig. 11 you can see an example of such a function machine used in a coordinate system showing the function $y=\frac{3}{4} x$. This means that when "putting" 4 into the function as the $x$-coordinate (abscissa) you get 3 as the $y$-coordinate (ordinate) - illustrated by the coordinate pair $(4,3)$.

To sum up, the foundation of this subconstruct is that the operator acts upon a quantity that is thereafter changed to a new quantity. This exchange creates a ratio between the input and the output quantity that is equal to the numerator-to-denominator ratio of the operator. Both unit equivalence and proportional equivalence are present in this subconstruct. The different interpretations of the operator subconstruct offer a means of understanding fraction multiplication (Lamon, 2012).

\subsection{Overview of equivalence within the subconstructs of fractions}

Having analysed the subconstructs of fractions to identify the presence of our equivalence conceptions, we found that the part-whole, operator, measure and quotient subconstructs involve both proportional and unit equivalence. The ratio subconstruct, which is founded on a proportional relation between the numerator and denominator, involved only proportional equivalence.

For the operator subconstruct, the fact that the input to output ratio of the function machine is equal to the fraction operator's ratio points to proportional equivalence. Additionally, when looking at Behr et al.'s $(1983,1993)$ stretcher-shrinker and duplicator/partition-reducer interpretations of this subconstruct, we find that it also involves unit equivalence. 


\section{Conceptual understanding of fraction addition and subtraction}

In the following sections, we analyse the role of equivalence in the conceptual understanding of fraction arithmetic. We have chosen to focus on the arithmetic operations of addition and subtraction rather than multiplication and division; however, studies have shown that proportional understanding is also an important part of fraction multiplication and division (Lamon, 2012). Furthermore, we have adopted the most common visual representations of fractions (e.g., circles, number lines and area models). The limitations of the circle model are that the circle representation has been criticised for only supporting additive thinking rather than the required multiplicative thinking when learning fractions (Moss, 2005), and recent studies have shown the advantages of using the number line over the area models (e.g., Hamdan \& Gunderson, 2017; Sidney, Thompson, \& Rivera, 2019). Therefore, we emphasise that visual representations remain a referent of fractions (Cramer \& Wyberg, 2009; Rau \& Matthews, 2017) but acknowledge that relations between iconic or visual representations and the referent fraction can be opaque, making it important to use diverse representations when teaching fractions.

However, it is beyond the scope of this article to go further into the discussion of the inherent limitations or strengths of each representation, but we stress that research has shown that the use of multiple models in learning fractions ensures that students develop a conceptual understanding of the multifaceted domain of fractions.

\subsection{Same denominator addition}

We start with a fraction addition arithmetic task: $\frac{1}{4}+\frac{1}{4}$. This can be calculated as $\frac{1}{4}+\frac{1}{4}=\frac{2}{4}=\frac{1}{2}$. It is essential that the interpretation of the two quarters is connected to equal wholes and parts since we must have the same unit in addition and subtraction. See example in Fig. 12.

A common mistake is to use whole number bias in the operation, where the numerators and denominators are seen as separate numbers and added: $\frac{1}{4}+\frac{1}{4}=\frac{2}{8}$ (Ni \& Zhou, 2005; Van Hoof, Verschaffel, \& Van Dooren, 2017). In many mathematics book systems, a pie chart representation is used to illustrate addition tasks, as shown in Fig. 13. Here, two $\frac{1}{4} \mathrm{~s}$ of a pie chart are added. The idea is that $\frac{2}{4}$ of the pie chart are coloured on the right-hand side of the equal sign. However, the equivalence is not correct when looking at the total number of slices on each side of the equal sign; it is only correct when looking at the grey slices. There are two grey slices on each side, but what about the white slices? There are six white slices on one side, but only two on the other side of

\section{Not equal-parts}

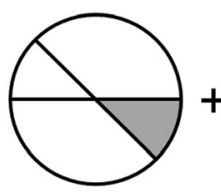

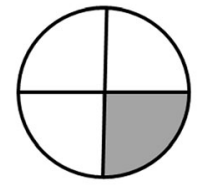

\section{Not equal-wholes}

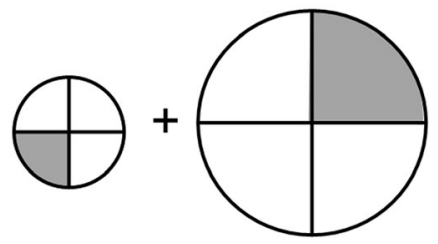

Fig. 12 Misconceptions - these are inaccurate representations of the task $\frac{1}{4}+\frac{1}{4}$ 


\section{Right result-wrong equivalence}

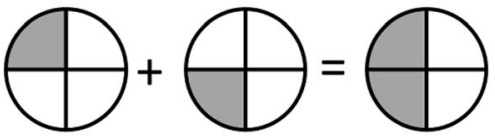

\section{Wrong result-right} equivalence
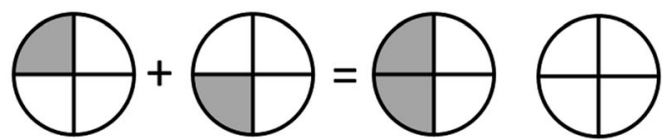

Fig. 13 The importance of choosing the right representations This is not an accurate representation of the task $\frac{1}{4}+\frac{1}{4}$

the equal sign-where did the other four white slices go? A fundamental problem in fractions is relating the part present to the underlying equal whole.

The size of a part cannot be determined without some kind of representation of the whole, but the two wholes should not be put together when adding. It is an important aspect of the part-whole subconstruct that the understanding of unit equivalence is developed rather than only recognising the proportional equivalence between different representations of fractions.

One way to overcome this obstacle is to emphasise that the white ('empty') parts of the representation of the whole are not as such part of the fraction in focus (see Fig. 14). They are only drawn to indicate the whole or unit. Another way is to use the number line as the representation instead of geometric shapes, e.g., circles, as the whole is often explicitly marked and therefore an integrated part of the number line. See examples in Fig. 14.

The measure subconstruct can solve the problem with the unit or whole. The unit is present on the number line and is kept constant; hence, the representation can include both the addend and the sum. In other words, the measure subconstruct supports that the students do not make the mistake of no equal-wholes, and this might be the reason why the number line seems to be a good representation compared to area models (e.g., Hamdan \& Gunderson, 2017; Sidney et al., 2019).

When looking at the understanding of equivalence connected to the first part of the computation $\frac{1}{4}+\frac{1}{4}=\frac{2}{4}$, it must be based on unit equivalence as just explained. In the example $\frac{1}{4}+\frac{1}{4}=\frac{2}{4}=\frac{1}{2}$, there is another equivalence present in the form of converting the result $\frac{2}{4}$ into $\frac{1}{2}$. To understand this equivalence, students can use whichever subconstruct they favour along with its corresponding equivalence conception.

a

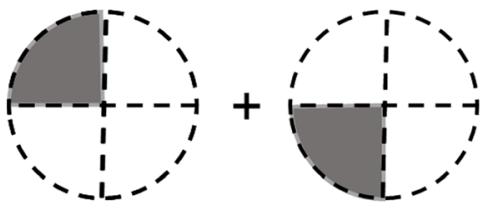

b

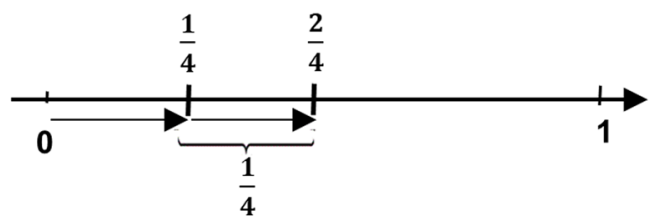

Fig. 14 Two accurate representations of the task $\frac{1}{4}+\frac{1}{4}$. It is important to emphasise that the dotted lines are indicating the implicit wholes. a Emphasis the present and non-present parts. b Finding the distance 


\subsection{Common denominator addition, fraction by a fraction}

When looking at addition tasks without a common denominator, such as $\frac{1}{3}+\frac{1}{4}$, we still need the two numbers to refer to the same unit. From an algorithmic perspective, a common approach to adding or subtracting fractions with different denominators is $\frac{a}{b}+\frac{c}{d}=\frac{a d+b c}{b d}$. This can also be written as $\frac{a}{b}+\frac{c}{d}=\frac{a d}{b d}+\frac{b c}{b d}=\frac{a d+b c}{b d}$, where the second calculation can be seen as an important step for understanding the equivalence, since we find fractions equivalent to $\frac{a}{b}$ and $\frac{c}{d}$ with the same denominator.

Learning $\frac{a}{b}+\frac{c}{d}=\frac{a d+b c}{b d}$ is a standard algorithmic approach, while $\frac{a}{b}+\frac{c}{d}=\frac{a d}{b d}+\frac{b c}{b d}=\frac{a d+b c}{b d}$ is a more conceptual approach because each of the two fractions, that are equal to each other, are present in the calculation. When looking at the explicit equivalence in the form of the equal sign in the example $\frac{1}{3}+\frac{1}{4}=\frac{4}{12}+\frac{3}{12}=\frac{7}{12}$, remember the transitive property, so that if $\frac{1}{3}+\frac{1}{4}=\frac{4}{12}+\frac{3}{12}$ and $\frac{4}{12}+\frac{3}{12}=\frac{7}{12}$, then $\frac{1}{3}+\frac{1}{4}=\frac{7}{12}$. When looking at this explicit equivalence, where there is equivalence between the two sides $\frac{1}{3}+\frac{1}{4}=\frac{4}{12}+\frac{3}{12}$, students will not necessarily understand that there is an equivalence between each fraction. Looking at $\frac{1}{3}+\frac{1}{4}=\frac{4}{12}+\frac{3}{12}$, we have two implicit equivalences: $\frac{1}{3}=\frac{4}{12}$ and $\frac{1}{4}=\frac{3}{12}$, as opposed to, for example, $5+3=4+4$, where 5 is not equal to 4 . When adding two fractions, they must be a fraction of the same whole; hence, the equivalence is unit equivalence. However, when expanding or reducing a fraction, any subconstruct can be used to understand the fraction; hence, the equivalence will be either unit or proportional equivalence, depending on the subconstruct used.

Finding the common denominator using the measure subconstruct can secure that the equal wholes are present, and as mentioned earlier, research has shown that especially the number line representation supports students' conceptual understanding of fractions (e.g., Hamdan \& Gunderson, 2017; Sidney et al., 2019). This might be explained by the fact that this representation includes equal wholes as shown in Fig. 15.

Finding the common denominator using the operator subconstruct can be seen as another way to illustrate and understand the concept (Fig. 16). The equivalence classes are measured on the $x$ - and $y$-axes, where the $x$-axis shows the denominator and the $y$-axis shows the numerator. When finding a common denominator, we must find the place where both fractions start with a whole number point in the denominator. Note that in the subconstructs, we found

a

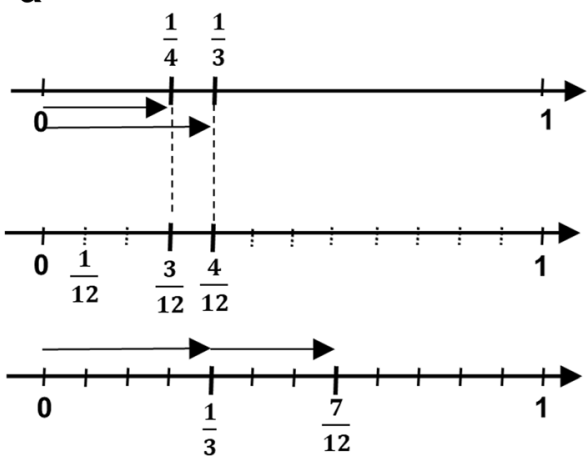

b

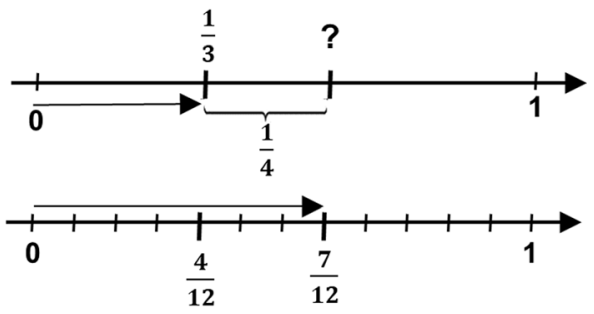

Fig. 15 Examples of the addition task $\frac{1}{3}+\frac{1}{4}=\frac{7}{12}$ in the measure subconstruct. a Finding the denominator $\frac{1}{3}+\frac{1}{4}$. b Finding the distance $\frac{1}{3}+\frac{1}{4}$ 


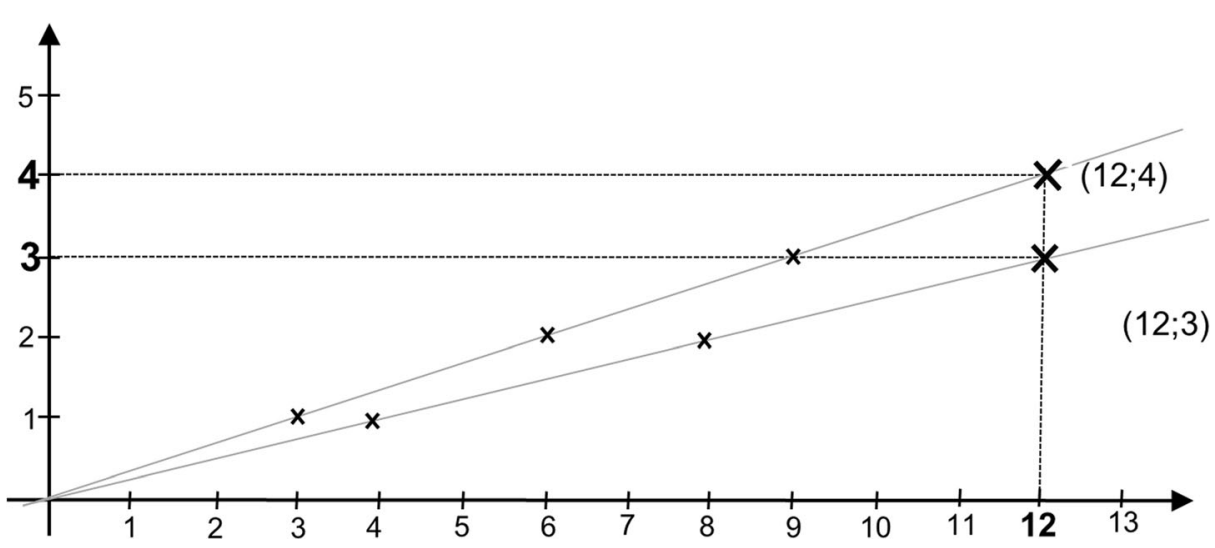

Fig. 16 Example of the operator subconstruct to find the common denominator

multiple ways to understand the two equivalence conceptions. This underlines the multidimensional constructs of fractions that students need to develop before they can flexibly handle fraction problems.

\subsection{Whole number subtracted by a fraction}

Understanding partitioning is essential for the conceptual understanding of subtraction algorithms. Partitioning or regrouping has many forms but often requires the understanding that, for example, $31=20+10+1=20+11$. Here, it is essential to understand that 31 is equivalent to $20+11$ (Ma, 1999). In regard to fractional arithmetic, a deeper understanding of partitioning is needed, for example, $\frac{3}{2}$ into $\frac{2}{2}$ and $\frac{1}{2}$, where the students use their understanding of unit equivalence to see that $\frac{2}{2}$ is equal to 1 , such that $\frac{3}{2}$ can be regrouped into $1+\frac{1}{2}$.

Partitioning is required when subtracting a fraction from a natural number. An example could be $2-\frac{1}{4}$. Here, one of the two wholes must be partitioned before the subtraction can be performed. This requires an understanding of the equivalence that 2 is equal to $1 \frac{4}{4}$ or $\frac{8}{4}$. That is, $2=1+\frac{4}{4}$ or $2=\frac{1}{4}+\frac{1}{4}+\ldots+\frac{1}{4}=\frac{8}{4}$, making it the same as eight groups of one quarter. This leads to a discussion of whether to use mixed numbers. The two different approaches for partitioning can be seen in Fig. 17.

In contrast to partitioning, using natural numbers (where partitioning into ones, tens and so on is the standard algorithm), the partitioning strategy for fraction subtraction is determined by the denominator of the fractions. It is essential for partitioning fractions that students have developed the understanding that equivalent fractions can have infinitely many different denominators. For example, when calculating $2-\frac{2}{5}$, it is possible to regroup 2 into 1 and $\frac{5}{5}$ or into $\frac{10}{5}$, but when calculating $2-\frac{1}{2}$, it is better to regroup 2 into 1 and $\frac{2}{2}$ or into $\frac{4}{2}$. This demonstrates the flexible use of equivalence.

The first approach shown in Fig. 17, regroup one, is aligned more closely with the standard algorithm for natural number subtraction, where one ten is 'borrowed' or 'exchanged'. Using this approach, only one of the wholes is partitioned into suitable parts, as determined by the denominator of the fraction. As in the natural number algorithm, there is no need to divide all the wholes; nor is there a need to 'exchange' more than 10 of the ones, tens or hundreds, etc. This might improve transfer between 


\section{Approach: Regrouping one}

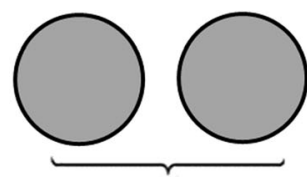

2

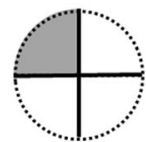

$\frac{1}{4}$
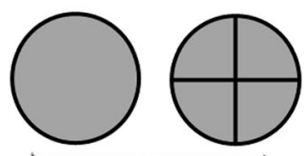

$1+$



$\frac{1}{4}$

\section{Approach: Regrouping all}

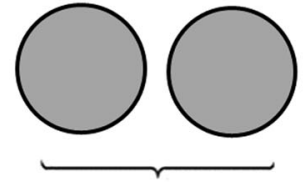

2

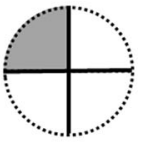

$\frac{1}{4}$
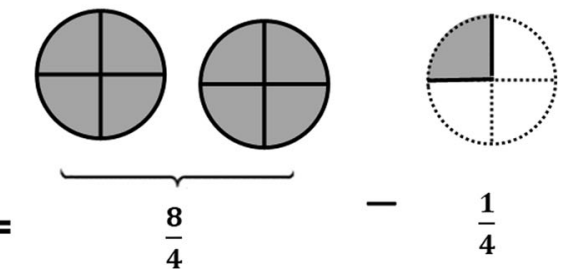

$\frac{1}{4}$

Fig. 17 Different regrouping approaches

knowledge of subtracting with natural numbers and knowledge of subtracting a fraction from a whole number.

The second subtraction approach regroup all seems easier looking at the algorithm (Fig. 17). Here, every whole is partitioned by the number detected by the denominator of the fraction. However, this approach does not have the same power to draw on students' knowledge of the natural number subtraction algorithm. Furthermore, it can be difficult to interpret the result. If it is larger than 1 , how big is it? How many wholes are there? Looking for example at the result of $\frac{7}{4}$, you could argue that this is a more suitable format than using a mixed number. The best option depends on the context of the task and the unit. For example, if it is pizza slices, $\frac{7}{4}$ might be a good result. If it is a recipe, $1 \frac{3}{4}$ cups of milk would be more suitable. If the result was $\frac{31}{4}$, you could argue that this is a division task rather than the final figure. Understanding equivalence is essential for students to recognise why each of these answers is correct and which notation style makes the most sense in each context.

\subsection{When multiplying, the denominator is not the easiest method}

Consider $\frac{2}{4}-\frac{1}{2}$. In this task, a student's use of the standard algorithm (finding a common denominator by multiplying the denominators) would indicate that they do not see $\frac{2}{4}$ as equivalent to $\frac{1}{2}$, thus recognising the equal magnitude of the fractions. When recognising that $\frac{2}{4}$ is equal to $\frac{1}{2}$, such that the task becomes $\frac{1}{2}-\frac{1}{2}$, the solution indicates that the student has a conceptual understanding of fractions and is able to solve subtraction tasks with different strategies. In a 2008 study, Newton showed that few preservice teachers used this easier strategy for subtracting fractions, revealing that they had only a procedural understanding of the topic (Newton, 2008). This raises the question of why do some people, but not others, recognise this equivalence? Would they also recognise that $\frac{18}{24}$ is equal to $\frac{3}{4}$ when solving $\frac{18}{24}-\frac{3}{4}$ ? 
Therefore, students need to learn to look at the fractions and their magnitude instead of always starting with the standard algorithm. We argue that several of Kieren's (1980) subconstructs support this more conceptual understanding of fractions.

Consider also $\frac{5}{6}-\frac{1}{4}$. The lowest common denominator is 12 ; however, if the standard algorithm of multiplying the two denominators is used, 24 would be the common denominator found. If students have already been taught prime factorisation, they will be able to find the lowest common denominator using prime decomposition. However, curriculums vary around the world (e.g., Lee, DeWolf, Bassok, \& Holyoak, 2016; Zhou, Peverly, \& Xin, 2006), and the presentation of fractions also varies across textbooks within each country (e.g., Cady, Hodges, \& Collins, 2015; Vasconcelos et al., 2017). Thus, we cannot assume that most elementary students will have learned this method. In addition, English and Halford (1995) argue against using only prime factorising. Therefore, this model does not lead the students to apply an understanding of equivalence. Arguably, students do not need to find the lowest common denominator because they could solve the task using the product of the two denominators.

However, it is important for students to develop the conceptual understanding that there are an infinite number of common denominators and infinitely many equivalent fractions. Hence, students' understanding should not be reduced to the procedural level, such that they think they can only subtract two fractions with different denominators if they multiply the denominators. Instead, we should strive to develop the conceptual understanding that the students can choose from among many different common denominators.

This understanding could also be linked to equivalence classes. Looking at the previous task, $\frac{5}{6}-\frac{1}{4}$, we can see two equivalence classes: $\frac{5}{6}=\frac{10}{12}=\frac{15}{18}=\frac{20}{24}=\frac{25}{30}=\frac{30}{36} \quad \ldots \quad$ and $\frac{1}{4}=\frac{2}{8}=\frac{3}{12}=\frac{4}{16}=\frac{5}{20}=\frac{6}{24}=\frac{7}{28}=\frac{8}{32}=\frac{9}{36} \ldots$ where $12,24,36$ and so on can be used as common denominators. It might be easiest to show this using the operator subconstruct, as shown in Fig. 16. The operation $\frac{5}{6}-\frac{1}{4}=\frac{10}{12}-\frac{3}{12}=\frac{7}{12}$ requires unit equivalence. Otherwise, we could have a situation in which the equal wholes are not balanced in the calculation (as in Fig. 12).

\section{Conclusion}

Our analysis of whether proportional equivalence and unit equivalence are present in the subconstructs of fractions has found that both equivalence conceptions are present in most of the subconstructs. The exception is the ratio subconstruct in which only proportional equivalence appears. These two equivalence conceptions create parallel interpretations of equivalent fractions.

With respect to the multifaceted concept of fractions, our analysis has revealed mathematical concepts and perspectives on equivalence that have not previously been combined with the semantic framework. Furthermore, we have identified different areas in which a knowledge of fraction equivalence is fundamental to a conceptual understanding of fraction arithmetic within addition and subtraction. This mathematical analysis of equivalence in the multifaceted construct of fraction gives new coherent relations between the different subconstructs.

\section{Implications for teaching}

Our analysis gives new insights that will help students to develop their conceptual understanding of fractions. More attention to the different conceptions of equivalence could provide 
a greater understanding of known fraction difficulties among students. Specifically, students' proficiency in both forms of equivalence might prepare them better for learning algebra, percentages and linear proportionality. For example, it is necessary to understand that the ratio stays the same when $\frac{2(3 a+5 b)}{4}=\frac{3 a+5 b}{2}$ is reduced.

Finally, this study supports the notion that fraction equivalence is required for conceptual understanding of fractions. Thus, rather than rushing into instructing students in the procedures and algorithms for performing operations on fractions, this study, in accordance with previous studies (e.g., Brousseau, Brousseau, \& Warfield, 2004; Lamon, 2012), recommends developing students' conceptual understanding of equivalence.

Yet, as previously mentioned, this should not lead to a rigid approach where students are forced through each subconstruct separately, and as Kieren (1976, 1980) also originally emphasised, the subconstructs are overlapping and interrelated to each other, wherefore students need to develop their understanding in interaction.

Acknowledgements We would like to thank Paul Andrews, Pernille Sunde, Henning Westphael, Pernille Pind, Erik Bjerre, Helle Hornemann, Tamsin Meaney and the anonymous reviewers for helpful comments on earlier drafts of this article. We are grateful to the Independent Research Fund Denmark and Via University College for supporting this research.

Materials availability Not applicable

Code availability Not applicable

Author contribution Pernille Ladegaard Pedersen designed the study, analysed and wrote the manuscript; Mette Bjerre analysed and wrote the manuscript.

Funding This research is funded by the Independent Research Fund Denmark and Via University College.

Data availability Not applicable

\section{Declarations}

Conflict of interest/Competing interests The authors declare no competing interests.

Open Access This article is licensed under a Creative Commons Attribution 4.0 International License, which permits use, sharing, adaptation, distribution and reproduction in any medium or format, as long as you give appropriate credit to the original author(s) and the source, provide a link to the Creative Commons licence, and indicate if changes were made. The images or other third party material in this article are included in the article's Creative Commons licence, unless indicated otherwise in a credit line to the material. If material is not included in the article's Creative Commons licence and your intended use is not permitted by statutory regulation or exceeds the permitted use, you will need to obtain permission directly from the copyright holder. To view a copy of this licence, visit http://creativecommons.org/licenses/by/4.0/.

\section{References}

Bailey, D. H., Hoard, M. K., Nugent, L., \& Geary, D. C. (2012). Competence with fractions predicts gains in mathematics achievement. Journal of Experimental Child Psychology, 113(3), 447-455. https://doi.org/10. 1016/J.JECP.2012.06.004 
Behr, M. J., Harel, G., Post, T., \& Lesh, R. (1992). Rational number, ratio, and proportion. In D. A. Grouws (Ed.), Handbook of research on mathematics teaching and learning: A project of the National Council of Teachers of Mathematics (pp. 296-333). New York, NY: Simon \& Schuster/Macmillan.

Behr, M. J., Harel, G., Post, T., \& Lesh, R. (1993). Rational numbers: Toward a semantic analysis_Emphasis on the operator construct. In T. P. Carpenter, E. Fennema, \& T. A. Romberg (Eds.), Rational numbers: An integration of research (pp. 13-48). Hillsdale, NJ: Lawrence Erlbaum Associates.

Behr, M. J., Lesh, R., Post, T. R., \& Silver, E. A. (1983). Rational-number concepts. In R. Lesh \& M. Landau (Eds.), Acquisition of mathematics concepts and processes (pp. 91-125). New York: Academic Press.

Behr, M. J., Wachsmuth, I., Post, T. R., \& Lesh, R. (1984). Order and equivalence of rational numbers: A clinical teaching experiment. Journal for Research in Mathematics Education, 15(5), 323-341.

Booth, J. L., \& Newton, K. J. (2012). Fractions: Could they really be the gatekeeper's doorman. Contemporary Educational Psychology, 37(4), 247-253. https://doi.org/10.1016/j.cedpsych.2012.07.001

Brousseau, G., Brousseau, N., \& Warfield, V. (2004). Rationals and decimals as required in the school curriculum: Part 1: Rationals as measurement. The Journal of Mathematical Behavior, 23(1), 1-20. https://doi.org/10.1016/j.jmathb.2003.12.001

Cady, J. A., Hodges, T. E., \& Collins, R. L. (2015). A comparison of textbooks' presentation of fractions. School Science and Mathematics, 115(3), 105-116. https://doi.org/10.1111/ssm.12108

Charalambous, C. Y., \& Pitta-Pantazi, D. (2007). Drawing on a theoretical model to study students' understandings of fractions. Educational Studies in Mathematics, 64(3), 293-316. https://doi.org/10.1007/s10649-0069036-2

Cramer, K., \& Wyberg, T. (2009). Efficacy of different concrete models for teaching the part-whole construct for fractions. Mathematical Thinking and Learning, 11(4), 226-257. https://doi.org/10.1080/ 10986060903246479

DeWolf, M., Chiang, J. N., Bassok, M., Holyoak, K. J., \& Monti, M. M. (2016). Neural representations of magnitude for natural and rational numbers. NeuroImage, 141, 304-312. https://doi.org/10.1016/j. neuroimage.2016.07.052

English, L., \& Halford, G. S. (1995). Mathematics education: Models and processes. New York, NY: Routledge.

Fazio, L. K., DeWolf, M., \& Siegler, R. S. (2016). Strategy use and strategy choice in fraction magnitude comparison. Journal of Experimental Psychology: Learning, Memory, and Cognition, 42(1), 1-16. https:// doi.org/10.1037/xlm0000153

Freudenthal, H. (1983). Didactical phenomenology of mathematical structures. Dordrecht, the Netherlands: Springer.

Hamdan, N., \& Gunderson, E. A. (2017). The number line is a critical spatial-numerical representation: Evidence from a fraction intervention. Developmental Psychology, 53(3), 587-596. https://doi.org/10.1037/ dev0000252

Hart, K. M. (1988). Ratio and proportion. In J. Hiebert \& M. J. Behr (Eds.), Number concepts and operations in the middle grades (pp. 198-219). Hillsdale, NJ: Lawrence Erlbaum Associates Inc..

Hecht, S. A., Close, L., \& Santisi, M. (2003). Sources of individual differences in fraction skills. Journal of Experimental Child Psychology, 86(4), 277-302. https://doi.org/10.1016/j.jecp.2003.08.003

Kamii, C., \& Clark, F. B. (1995). Equivalent fractions: Their difficulty and educational implications. The Journal of Mathematical Behavior, 14(4), 365-378. https://doi.org/10.1016/0732-3123(95)90035-7

Kaput, J. J., \& West, M. M. (1994). Missing-value proportional reasoning problems: Factors affecting informal reasoning patterns. In G. Harel \& J. Confrey (Eds.), The development of multiplicative reasoning in the learning of mathematics (pp. 235-287). Albany, NY: State University of New York Press.

Kieren, T. E. (1976). Number and measurement: Papers from a research conference. In R. A. Lesh \& D. A. Bradbard (Eds.), On the mathematical, cognitive, and instructional foundations of rational numbers (pp. 101-144). Columbus, OH: ERIC/SMEAC.

Kieren, T. E. (1980). The rational number construct-Its elements and mechanisms. In T. E. Kieren (Ed.), Recent research on number learning (pp. 125-150). Columbus, OH: ERIC Clearinghouse for Science, Mathematics and Environmental Education.

Kieren, T. E. (1988). Rational and fractional numbers as mathematical and personal knowledge: Implications for curriculum and instruction. In J. Hiebert \& M. Behr (Eds.), Number concepts and operations in the middle grades (pp. 162-181). Reston, VA: Lawrence Erlbaum.

Kieren, T. E. (1993). Rational and fractional numbers: From quotient fields to recursive understanding. In T. P. Carpenter, E. Fennema, \& T. A. Romberg (Eds.), Rational numbers: An integration of research (pp. 49-84). Hillsdale, NJ: Lawrence Erlbaum Associates.

Lamon, S. J. (2007). Rational numbers and proportional reasoning: Towards a theoretical framework for research. In F. K. Lester (Ed.), Second handbook of research on mathematics teaching and learning (pp. 629-667). Reston, VA: Lawrence Erlbaum. 
Lamon, S. J. (2012). Teaching fractions and ratios for understanding: Essential content knowledge and instructional strategies for teachers. New York, NY: Routledge.

Lee, H. S., DeWolf, M., Bassok, M., \& Holyoak, K. J. (2016). Conceptual and procedural distinctions between fractions and decimals: A cross-national comparison. Cognition, 147, 57-69. https://doi.org/10.1016/j. cognition.2015.11.005

Ma, L. (1999). Knowing and teaching elementary mathematics. Mahwah, NJ: Lawrence Erlbaum.

Marshall, S. P. (1993). Assessment of rational number understanding: A schema-based approach. In T. P. Carpenter, E. Fennema, \& T. A. Romberg (Eds.), Rational numbers: An integration of research (pp. 261288). Hillsdale, N.J: Lawrence Erlbaum Associates.

Moss, J. (2005). Pipes, tubes, and beakers: New approaches to teaching rational-number system. In M. Donovan \& J. D. Bransford (Eds.), How students learn: Mathematics in the classroom (pp. 309-350). Washington, D.C.: The National Academies Press.

Newton, K. J. (2008). An extensive analysis of preservice elementary teachers' knowledge of fractions. American Educational Research Journal, 45(4), 1080-1110. https://doi.org/10.3102/0002831208320851

Ni, Y. (2001). Semantic domains of rational numbers and the acquisition of fraction equivalence. Contemporary Educational Psychology, 26(3), 400-417. https://doi.org/10.1006/ceps.2000.1072

Ni, Y., \& Zhou, Y. D. (2005). Teaching and learning fraction and rational numbers: The origins and implications of whole number bias. Educational Psychologist, 40(1), 27-52. https://doi.org/10.1207/ s15326985ep4001_3

Ohlsson, S. (1987). Sense and reference in the design of interactive illustrations for rational numbers. In R. W. Lawler \& M. Yazdani (Eds.), Artificial intelligence and education: Learning environments and tutoring systems (pp. 313-350). New Jersey: Intellect Books.

Olive, J., \& Lobato, J. (2008). The learning of rational number concepts using technology. In M. K. Heid \& G. W. Blume (Eds.), Research on technology and the teaching and learning of mathematics: Research syntheses (pp. 1-54). Charlotte, NC: Information Age.

Peck, D. M., \& Jencks, S. M. (1981). Conceptual issues in the teaching and learning of fractions. Journal for Research in Mathematics Education, 12(5), 339-348.

Rau, M. A., \& Matthews, P. G. (2017). How to make 'more' better? Principles for effective use of multiple representations to enhance students' learning about fractions. ZDM-International Journal on Mathematics Education, 49(4), 531-544. https://doi.org/10.1007/s11858-017-0846-8

Schneider, M., \& Siegler, R. S. (2010). Representations of the magnitudes of fractions. Journal of Experimental Psychology: Human Perception and Performance, 36(5), 1227-1238. https://doi.org/ $10.1037 / \mathrm{a} 0018170$

Sidney, P. G., Thompson, C. A., \& Rivera, F. D. (2019). Number lines, but not area models, support children's accuracy and conceptual models of fraction division. Contemporary Educational Psychology, 58, 288-298. https://doi.org/10.1016/j.cedpsych.2019.03.011

Siegler, R. S., Duncan, G. J., Davis-Kean, P. E., Duckworth, K., Claessens, A., Engel, M., ... Chen, M. (2012). Early predictors of high school mathematics achievement. Psychological Science, 23(7), 691-697. https:// doi.org/10.1177/0956797612440101

Siegler, R. S., Fazio, L. K., Bailey, D. H., \& Zhou, X. (2013). Fractions: The new frontier for theories of numerical development. Trends in Cognitive Sciences, 17(1), 13-19. https://doi.org/10.1016/j.tics.2012.11. 004

Smith, J. P. (1995). Competent reasoning with rational numbers. Cognition and Instruction, 13(1), 3-50. https:// doi.org/10.1207/s1532690xci1301_1

Stafylidou, S., \& Vosniadou, S. (2004). The development of students' understanding of the numerical value of fractions. Learning and Instruction, 14(5 SPEC.ISS), 503-518. https://doi.org/10.1016/j.learninstruc.2004. 06.015

Streetland, L. (1991). Fractions in realistic mathematics education: A paradigm of developmental research. Dordrecht, the Netherlands: Kluwer Academic Publishers.

Torbeyns, J., Schneider, M., Xin, Z., \& Siegler, R. S. (2015). Bridging the gap: Fraction understanding is central to mathematics achievement in students from three different continents. Learning and Instruction, 37, 5-13. https://doi.org/10.1016/j.learninstruc.2014.03.002

Tzur, R. (1999). An integrated research on children's construction of meaningful, symbolic, partitioning-related conceptions, and the teacher's role in fostering that learning. The Journal of Mathematical Behavior, 18(2), 123-147. https://doi.org/10.1016/s0732-3123(99)00025-5

Vamvakoussi, X. (2015). The development of rational number knowledge: Old topic, new insights. Learning and Instruction, 37, 50-55. https://doi.org/10.1016/j.learninstruc.2015.01.002

Van Hoof, J., Lijnen, T., Verschaffel, L., \& Van Dooren, W. (2013). Are secondary school students still hampered by the natural number bias? A reaction time study on fraction comparison tasks. Research in Mathematics Education, 15(2), 154-164. https://doi.org/10.1080/14794802.2013.797747 
Van Hoof, J., Verschaffel, L., \& Van Dooren, W. (2017). Number sense in the transition from natural to rational numbers. British Journal of Educational Psychology, 87(1), 43-56. https://doi.org/10.1111/ bjep. 12134

Vasconcelos, I. C. P., da Mamede, E. P. B. C., \& Dorneles, B. V. (2017). The comprehension of numerical relationships in the learning of fractions: A comparative study with Brazilian and Portuguese children. Revista Brasileira de Estudos Pedagógicos, 98(249), 251-269. https://doi.org/10.24109/2176-6681.rbep. 98i249.3043

Vergnaud, G. (1983). Multiplicative structures. In R. Lesh \& M. Landau (Eds.), Number concepts and operations in the middle grades (pp. 127-174). New York: Academic Press.

Wong, M. (2010). Equivalent fractions: Developing a pathway of students' acquisition of knowledge and understanding. In L. Sparrow, B. Kissane, \& C. Hurst (Eds.), Shaping the Future of Mathematics Education: Proceedings of the 33rd annual conference of the Mathematics Education Research Group of Australasia (pp. 673-680). Fremantle, WA: MERGA.

Wong, M., \& Evans, D. (2007). Students' conceptual understanding of equivalent fractions. In J. Watson \& K. Beswick (Eds.), Proceedings of the 30th annual conference of the Mathematics Education Research Group of Australasia (pp. 824-833). Adelaide, SA: MERGA.

Yoshida, H., \& Kuriyama, K. (1995). Linking meaning of symbols of fractions to problem situations. Japanese Psychological Research, 37(4), 229-239. https://doi.org/10.4992/psycholres1954.37.229

Yoshida, H., \& Sawano, K. (2002). Overcoming cognitive obstacles in learning fractions: Equal-partitioning and equal-whole. Japanese Psychological Research, 44(4), 183-195.

Zhou, Z., Peverly, S. T., \& Xin, T. (2006). Knowing and teaching fractions: A cross-cultural study of American and Chinese mathematics teachers. Contemporary Educational Psychology, 31(4), 438-457. https://doi.org/ 10.1016/j.cedpsych.2006.02.001

Publisher's note Springer Nature remains neutral with regard to jurisdictional claims in published maps and institutional affiliations. 